\title{
What Do You Do When Things Go Right? The Intrapersonal and Interpersonal Benefits of Sharing Positive Events
}

\author{
Shelly L. Gable \\ University of California, Los Angeles \\ Emily A. Impett \\ University of California, Los Angeles
}

\author{
Harry T. Reis \\ University of Rochester \\ Evan R. Asher \\ University of Rochester
}

\begin{abstract}
Four studies examined the intrapersonal and interpersonal consequences of seeking out others when good things happen (i.e., capitalization). Two studies showed that communicating personal positive events with others was associated with increased daily positive affect and well-being, above and beyond the impact of the positive event itself and other daily events. Moreover, when others were perceived to respond actively and constructively (and not passively or destructively) to capitalization attempts, the benefits were further enhanced. Two studies found that close relationships in which one's partner typically responds to capitalization attempts enthusiastically were associated with higher relationship well-being (e.g., intimacy, daily marital satisfaction). The results are discussed in terms of the theoretical and empirical importance of understanding how people "cope" with positive events, cultivate positive emotions, and enhance social bonds.
\end{abstract}

Good, the more communicated, more abundant grows. —John Milton, Paradise Lost, Book V

The puzzle of well-being has many pieces. One piece that has been the focus of much research is how people maintain or restore their well-being in the face of negative events or stressors. Research has often asked, "What can people do when things go wrong?" and useful answers to this question have come from studies on appraisals (e.g., Folkman, Lazarus, Dunkel-Schetter, Delongis, \& Gruen, 1986; Lazarus, 1991), coping (e.g., Bolger, 1990; Carver \& Scheier, 1994), and rumination (e.g., NolenHoeksema, 1996, 1998). These and other studies have demonstrated that people routinely turn to others for support in times of stress, be it in the face of everyday stressors (e.g., Harlow \& Cantor, 1995) or major life events (e.g., Bolger \& Eckenrode, 1991), and that the availability of social support has clear benefits for the support-seeker's health and well-being (e.g., Sarason, Sarason, \& Gurung, 1997; Uchino, Cacioppo, \& Kiecolt-Glaser, 1996). Furthermore, people commonly cite the possibility of receiving

Shelly L. Gable and Emily A. Impett, Department of Psychology, University of California, Los Angeles; Harry T. Reis and Evan R. Asher, Department of Clinical and Social Sciences in Psychology, University of Rochester.

Study 2 was supported by a Barth-Crapsey award from the University of Rochester, Study 3 was collected as part of Shelly L. Gable's doctoral dissertation (Gable, 2000, Study 2), and Study 4 was supported by a grant from the Templeton Foundation/Positive Psychology Network awarded to Shelly L. Gable.

Correspondence concerning this article should be addressed to Shelly L. Gable, Department of Psychology, University of California, Los Angeles, 4560 Franz Hall, Box 951563, Los Angeles, CA 90095-1563. E-mail: gable@psych.ucla.edu social support, if and when needed, as one of the major benefits of close relationships (e.g., Cunningham \& Barbee, 2000). Without doubt, the processes involved in utilizing social relations to cope with negative events are central to understanding intrapersonal and interpersonal well-being. Nevertheless, this article suggests that another, complementary piece of the puzzle has been largely overlooked: the intrapersonal and interpersonal consequences of seeking out others when good things happen.

Although the social sharing of good news has received relatively little attention, research on responses to good fortune has not been entirely lacking. For example, in two daily experience studies, Langston (1994) found that when people shared the news of a positive event with others or celebrated the event in some way, they experienced greater positive affect, beyond increases associated with the valence of the positive event itself. He called this capitalization, a term that we adopt to refer to the process of informing another person about the occurrence of a personal positive event and thereby deriving additional benefit from it. Langston's findings complement research by Bryant (1989), who found that individual differences in the self-reported ability to savor positive events were correlated with subjective well-being. These studies also complement research by Tesser and his colleagues on the extended self-evaluation maintenance model (e.g., Beach \& Tesser, 1995; Tesser, 2000), which demonstrates that reflection processes - that is, the ability to share in a partner's success-contribute to emotional well-being and relationship satisfaction. The present research seeks to extend these studies by investigating the intrapersonal and interpersonal outcomes associated with capitalizing on positive events. Paralleling existing research on stressors and social support, we examined both the process of seeking a response to one's good fortune and the impact of perceiving the provision of a positive response. 


\section{Positive Events and Well-Being}

Traditionally, researchers interested in health and well-being have examined the psychological and physical consequences of stressors and other negative events (e.g., Cohen \& Wills, 1985; Hobfoll, 1998; Taylor, 1991). Recent theorizing has suggested that processes linked to positive events may have independent and important associations with well-being and health (e.g., Reis \& Gable, 2003; Ryff \& Singer, 1998). For example, Lewinsohn and Graf (1973) found that everyday pleasant events were associated with decreases in depressive symptoms (Zautra, Schultz, \& Reich, 2000). More recently, Nezlek and Gable (2001) found that the occurrence of minor positive events was associated with increases in daily self-esteem and perceived control and decreases in daily depressive cognitions, above and beyond the effect of negative events.

That positive events may have independent effects on wellbeing, over and above the impact of negative events, is consistent with the extensive research demonstrating the independence of appetitive and aversive processes (Gable \& Reis, 2001; Higgins, 1997). This independence has been most clearly established in studies of emotion, in which the processes regulating positive and negative emotions are functionally independent (Cacioppo \& Gardner, 1999). For example, Gable, Reis, and Elliot (2000) showed that everyday positive events were associated with increased positive affect but not with changes in negative affect. Other studies showing that positive, pleasant, or desirable events are differentially related to positive but not negative affect include L. A. Clark and Watson (1988) and David, Green, Martin, and Suls (1997). If positive events are uniquely and distinguishably associated with positive emotions, then it becomes important to investigate how people "cope" ${ }^{1}$ with positive events, inasmuch as these processes may differ from the processes involved in coping with negative events (which include social support). In fact, positive emotions appear to have important consequences for health and well-being over and above negative emotions, as recent studies have shown (Salovey, Rothman, Detweiler, \& Steward, 2000). For example, Pettit, Kline, Gencoz, and Gencoz (2001) found that positive affectivity but not negative affectivity predicted selfreported health. Danner, Snowdon, and Friesen (2001) found that positive emotional expression in autobiographical statements inversely predicted mortality 6 decades later. Similarly, Harker and Keltner (2001) showed that the expression of positive emotion in college yearbook photos predicted well-being 30 years later.

In a recent and influential article, Fredrickson (1998) suggested that positive emotions have received insufficient attention because they do not fit existing models of emotion and emotion regulation. To fill this gap, Fredrickson $(1998,2001)$ has proposed a "broaden-and-build" theory of positive emotions. This theory posits that the function of positive emotions is to broaden an individual's thought-action repertoire (that is, to facilitate a broader scope of cognition, attention, and action) and to build resources (that is, to enhance the individual's physical, intellectual, and social resources). Preliminary evidence supports this model. For example, Fredrickson and Joiner (2002) found that broad-minded coping (i.e., flexible cognitive responses to stressors) was associated with increased positive emotions and an upward spiral toward increased well-being. Empirical evidence for the broaden-and-build model of positive emotions has predominantly focused on the broadening component of the theory (e.g., Fredrickson \& Branigan, 2002; Fredrickson \& Joiner, 2002). The capitalization process, we suggest, is central to the process of using positive emotions to build resources.

\section{Capitalization Builds Personal and Social Resources}

We propose that capitalization-telling others about positive events in one's life-is likely to generate additional positive affect, over and above positive affect associated with the event itself. There are several possible mechanisms for such an effect. First, sharing a positive event with others requires retelling the event, which creates an opportunity for reliving and reexperiencing the event. Furthermore, the communicative act may involve rehearsal and elaboration, both of which seem likely to prolong and enhance the experience by increasing its salience and accessibility in memory. If so, positive events that are communicated to others should be remembered better than positive events not communicated.

Another potential mechanism is more interpersonal in nature. Sharing events with others may build social resources by fostering positive social interactions, which are reinforcing in and of themselves (Gable \& Reis, 2001), and thereby strengthening relationships. Furthermore, sharing good news initiates an interaction that may allow individuals to perceive that others are pleased for them, a process likely to boost self-esteem (e.g., Beach \& Tesser, 1995; Tesser, Millar, \& Moore, 1988) and more generally to facilitate positive reflected appraisals-perceiving oneself positively in the eyes of the other (Baumeister, 1998; Leary \& Baumeister, 2000; Shrauger \& Schoeneman, 1979). This latter effect requires, of course, that the listener's response be experienced as positivethat is, as recognizing and validating the good news (Reis \& Patrick, 1996). More destructive responses (for example, pointing out the downside of a positive event or minimizing its importance) may well dampen or even reverse the positive affect produced by one's good fortune. Thus, we propose that the personal and social resources to be gained from capitalization depend in an important way on the ability to perceive the other's response as positive. This process provides one central mechanism, we suggest, for the upward spiral of positive affect and well-being described by Fredrickson (1998).

\section{Capitalization and Responsiveness to the Self}

As proposed above, capitalization may depend significantly on the ability to perceive the partner's response as supporting one's good fortune. People are unlikely to share their good news if they anticipate rejection, defensiveness, or an otherwise unappreciative response. Supportive responses suggest that an interaction partner is pleased for one, and this may be diagnostic not only of the partner's positive evaluation of the event itself but also of the relationship. One reason for this is that an enthusiastic response may indicate that the partner is "basking in reflected glory" (Cialdini et al., 1976) — feeling that the good fortune rubs off to some

\footnotetext{
${ }^{1}$ Although the use of the word cope has traditionally referred to how people deal with negative events, we extend this meaning to responses to positive events.
} 
extent on themselves, a process that at least nominally imputes a relationship between self and partner. This tendency is likely to be enhanced the closer the relationship (Beach \& Tesser, 1995). Aron, Aron, Tudor, and Nelson (1991) defined closeness as "including the other in the self," a process that implies that a partner's good fortune may psychologically be experienced as one's own in a close relationship (over and above whatever material consequences a partner's good fortune may have for the self). Thus, a partner's response of genuine pleasure to one's capitalization attempts may indicate a sense of connection. Research on empathy and emotional contagion, although not usually focused on positive events, points to a similar conclusion (Hatfield, Cacioppo, \& Rapson, 1994).

Similarly, a constructive response may engender processes central to the intimacy process. As Reis and Shaver (1988) defined that process, disclosure of self-relevant material fosters intimacy when the partner's response is experienced as understanding, validating, and caring. The partner's response is critical to this process because it indicates that he or she is aware of central aspects of the self (which include goal attainment, positive affects, and the personally relevant activities that foster them) and is willing and able to be empathic and supportive. In fact, as Reis, Clark, and Holmes (2004) have recently suggested, "perceived responsiveness to the self" is a central idea behind numerous self-relevant interpersonal processes, such as attachment theory (Mikulincer \& Shaver, 2003), rejection sensitivity (Downey, Freitas, Michaelis, \& Khouri, 1998), the construction of a sense of felt security (Murray \& Holmes, 1993), mutual cyclical growth (Rusbult, Olsen, Davis, \& Hannon, 2001), and communal caring (M. S. Clark, Fitness, \& Brissette, 2001). Typically, however, perceived responsiveness is conceptualized and investigated in terms of responses either to negative events or to nominally private information whose public disclosure might leave one vulnerable. We propose that the concept of responsiveness may also apply to personal positive events by revealing whether or not a partner is pleased for one, an act that incorporates evaluations of the event, its self-relevance, and the relationship.

\section{Overview of the Research and Hypotheses}

The present research was designed to examine the intrapersonal and interpersonal correlates of sharing positive events with others (i.e., capitalization). We first sought to establish that the sharing of good news has beneficial intrapersonal effects. Study 1 was a daily experience study in which participants reported on the sharing (or not) of positive events and their daily affect and well-being. On the basis of previous research and Fredrickson's (1998) broaden-andbuild model, we predicted that capitalization would be associated with increased positive affect and subjective well-being, beyond variance associated with the positive event itself. We further predicted that capitalization would be uncorrelated with negative affect.

In Studies 2 and 3, we examined the interpersonal correlates of perceived responsiveness of others to capitalization attempts in dating and married couples, respectively. We predicted that close relationships in which partners are perceived to respond to the sharing of positive events in a constructive rather than a destructive manner would be more satisfying, intimate, and trusting.
Moreover, we predicted that perceived responses to capitalization attempts would account for variance in relationship quality over and above responses to conflict and other negative events.

Study 4 simultaneously investigated daily correlates of the sharing of good news and perceived partner responses. We also examined one possible mechanism linking capitalization and its outcomes, namely, memory for the event. As suggested above, capitalizing on positive events may enhance their memorability, perhaps because retelling the event provides opportunities for rehearsal and elaboration. In contrast, we hypothesize that the sharing of negative events will not improve their memorability, because the goal of social support seeking is often to "let go" of the negative event or at least to minimize its impact, rendering it less accessible in memory.

\section{Study 1 \\ Method}

\section{Participants and Procedure}

Participants were 154 undergraduates (56 men and 98 women) who received extra credit toward psychology coursework. Ages ranged from 17 to 26 years $(M=19.7, S D=1.3){ }^{2}$ At the beginning of the study, participants were given seven booklets containing the daily measures, one for each night of the week. To bolster and verify compliance with the diary schedule, participants were instructed to return completed diaries early the next day at a table located in the student union or before class (on class days). As an incentive, whenever participants handed in a booklet on time, they received a lottery ticket for prizes for a raffle to be held after the study. Only booklets returned on time were treated as valid and retained in the data set. Participants completed 781 days on time, an average of 5.1 days per person.

\section{Measures}

Positive and negative affect. The Positive and Negative Affect Schedule (PANAS; Watson, Clark, \& Tellegen, 1988) was used to measure daily Activated Positive Affect (PA) and Activated Negative Affect (NA). The PANAS consists of 10 positive and 10 negative emotion adjectives and was reliable, with internal consistencies of .91 and .89 , respectively. The PA and NA scales are also relatively independent; correlations for daily ratings were -.12 (at the person level, $N=154$ ) and -.14 (at the day level, $N=$ 765 ) in the current study.

Life satisfaction. Diener's (1996) five-item Satisfaction With Life Scale was used to assess satisfaction with life. Participants responded to each item using a 5-point scale (disagree to agree) according to how they felt on that day. The example items were "Today, in most ways my life was close to my ideal" and "I was satisfied with my life today." The internal consistency coefficient for this scale was .93.

Negative and positive event. For the negative event, participants were asked to briefly describe "the most important problem or stressful event or issue of the day." They were instructed that this may "be something that happened today, something that happened in the past that affected you today, or something you anticipate happening in the future." Three blank lines were provided for their description. Participants then rated how stressful the event was on a 5-point scale $(M=3.70, S D=1.02)$. Participants described a range of daily stressors in social, school, work,

\footnotetext{
${ }^{2}$ These data were part of a larger daily experience study. A detailed description of the sample is provided in Gable et al. (2000, Study 3).
} 
health, and financial domains that varied in severity-for example, "running out of money on my keycard," "performed poorly on my organic chem. exam," "spoke to someone about something they did that hurt me," "friend broke his neck in an accident." Coders rated the domain of each event: $31.7 \%$ concerned social relationships (of which $13.0 \%$ concerned a romantic relationship), $38.9 \%$ were about schoolwork, $8.7 \%$ concerned health or body issues (e.g., exercising, weight, illness, sleep deprivation), and the remaining $21.0 \%$ concerned job, financial, or other nonsocial events.

Participants were also asked to briefly describe "the most import positive event or issue of the day." As with the negative events, participants were told that the event or issue could be something that happened today, in the past, or that they anticipated happening in the future. Participants then rated, on a 5-point scale, how important the positive event was to them $(M=4.13, S D=0.92)$. Participants described a range of positive events in social, school, and work domains-for example, "I received a surprise care package from my sister," "MCAT scores came today, and they were very good," "Got a phone call from my best friend in Venezuela," "I was accepted into graduate school today." Coders rated the domain of each event, and $57.3 \%$ concerned social relationships (of which $15.0 \%$ involved a romantic partner, $5.0 \%$ involved family, $30.5 \%$ involved friends, and $6.8 \%$ involved others), $17.5 \%$ concerned schoolwork, $7.3 \%$ involved health and body, and the remaining $17.9 \%$ involved job, finances, or other nonsocial events.

Capitalization attempts. Participants were asked how much they "let others know about the event/issue" using a 5-point scale (from not at all to very much). From this item we were also able to compute a simple dichotomous measure of whether or not participants had shared the event with another person, in which responses of 1 were coded as "did not share" and 2-5 were considered as "did share." Both the dichotomous and continuous variables were used in subsequent analyses and produced nearly identical results. We focus on the dichotomous measure for simplicity. Social events did not differ from nonsocial events in the likelihood of being shared, $\chi^{2}(1, N=761)=1.18, p=.28$.

Additional measures. To control for other events of the day, participants indicated whether or not each of 17 positive and 19 negative events had occurred on that day (for a detailed description, see Gable et al., 2000). A frequency score for positive and negative events was tabulated for each participant, each day. Participants also completed the Neuroticism and Extraversion scales from the short-scale Eysenck Personality Questionnaire-Revised (Eysenck, Eysenck \& Barrett, 1985) to control for possible individual differences.

\section{Results}

Participants told someone else about their most positive event on $70.8 \%$ of days. As expected, they were more likely to share more important positive events than less important events. The average correlation across days between event importance and the continuous rating of having told others was .26 ( $p<.05)$. In all subsequent analyses, the importance rating for the most significant positive event was controlled. In addition, the stress rating for the most negative event of the day was also included in subsequent analyses in order to assess associations among positive events, capitalization, and outcomes, independent of the impact of negative events.

\section{Data Analysis Strategy}

Because the data were hierarchical-days nested within person-multilevel modeling was used for analyses. We used the Hierarchical Linear Modeling (HLM) program (HLMwin v.5.02;
Raudenbush, Bryk, Cheong, \& Congdon, 2000), which simultaneously addresses both levels in a hierarchically nested data set and provides independent estimates of the relationships among constructs at the lower level (within persons) and models them at the upper level (between persons) as a random effect. A series of three HLM equations was constructed to examine relationships between capitalization and the three outcome variables. The Level 1 equation for PA was as follows:

$$
\begin{array}{r}
\mathrm{PA}_{i j}=b_{0 j}+b_{1 j}\left(\mathrm{NEG} \_E V E N T_{i j}\right)+b_{2 j}\left(\mathrm{POS} \_E V E N T_{i j}\right) \\
+b_{3 j}\left(\mathrm{CAP}_{i j}\right)+r_{i j},
\end{array}
$$

where $b_{0 j}$ refers to the intercept (i.e., the person's PA on an average day); $b_{1 j}$ and $b_{2 j}$ represent slopes between PA and stressfulness ratings of the negative event and importance ratings of the positive event of the day, respectively; $b_{3 j}$ represents the slope between daily PA and the dichotomous variable indicating whether or not the participant shared the positive event with someone else; and $r_{i j}$ represents error. Negative and positive event importance ratings were centered around each participant's mean, and therefore the coefficients represent the degree to which rated event importance on the $i$ th day deviated from the person's average event importance rating. Thus, person $j$ 's PA on the $i$ th day is predicted from his or her average PA $\left(b_{0 j}\right)$, the stressfulness of each day's most negative event weighted by its coefficient $\left(b_{1 j}\right)$, the importance of each day's most positive event weighted by its coefficient $\left(b_{2 j}\right)$, and whether they shared the event weighted by its coefficient $\left(b_{3 j}\right)$, plus error $\left(r_{i j}\right)$. Person-level effects were estimated as follows:

$$
\begin{aligned}
& b_{0 j}=g_{00}+u_{0 j}, \\
& b_{1 j}=g_{10}+u_{1 j}, \\
& b_{2 j}=g_{20}+u_{2 j}, \\
& b_{3 j}=g_{30}+u_{3 j},
\end{aligned}
$$

where $g_{x 0}$ represents the samplewide day-level intercept and slopes, and $u_{x j}$ represents residual variances of the intercepts between persons (a random effect). Interpretation of coefficients $b_{1}-b_{3}$ is as follows: Each unit increase in the predictor variable (e.g., positive event importance) is associated with that many units of change in the outcome variable (e.g., PA).

\section{Findings}

Table 1 shows results for three models predicting PA, NA, and life satisfaction, respectively. On days people shared the occurrence of a positive event with others, they reported significantly higher PA and life satisfaction, above and beyond the importance of the most positive and most negative event of the day. NA was not significantly diminished by the sharing of a positive event. Identical equations were computed using the continuous sharing variable (i.e., the degree to which participants had shared the positive event) and produced similar results (i.e., all significant 
Table 1

Capitalization and Daily Positive Affect (PA), Negative Affect (NA), and Satisfaction With Life (Study 1)

\begin{tabular}{lccr}
\hline & \multicolumn{3}{c}{ Outcome } \\
\cline { 2 - 4 } \multicolumn{1}{c}{ Predictor } & $\mathrm{PA}$ & $\mathrm{NA}$ & Satisfaction \\
\hline Negative event importance & $-.09 * *$ & $.23 * *$ & $-.26^{* *}$ \\
Positive event importance & $.07 *$ & -.02 & $.17^{* *}$ \\
Capitalization $^{\mathrm{a}}$ & $.20^{* *}$ & -.06 & $.23 * *$ \\
\hline
\end{tabular}

Note. $\quad N=154$. Coefficients are unstandardized hierarchical linear modeling coefficients.

${ }^{a}$ Dichotomous variable representing whether or not participant shared the occurrence of the positive event with someone.

$* p<.05 . \quad * * p<.01$.

coefficients remained significant and nonsignificant coefficients remained nonsignificant). ${ }^{3}$

Several additional equations were examined to address possible confounds. First, the number of positive and negative events (from the separate checklist measure) experienced during the day were added as additional predictors of the outcomes. Capitalization remained a significant predictor of $\mathrm{PA}$ and of life satisfaction $(p s<.01)$. Second, neuroticism and extraversion were entered in Equation 2 as moderators of the coefficients. Again, capitalization remained a significant predictor of PA and of life satisfaction $(p s<.01)$.

\section{Brief Summary of Study 1 and Overview of Studies 2 and 3}

Study 1 replicated and extended the findings of Langston (1994) by showing that positive affect and life satisfaction were higher on days people shared the occurrence of their most positive event of the day. Moreover, we tested several alternative within- and between-person explanations and found that the hypothesized effects remained significant, controlling for the importance of their positive event, the importance of their most stressful daily event, the number of positive and negative events experienced that day, and individual differences in neuroticism and extraversion.

Studies 2 and 3 examined interpersonal consequences of the capitalization process. If the benefits of capitalization derive from building social resources, then the manner in which a significant other is perceived to respond to one's capitalization attempts should determine whether or not these attempts are effective. Of course, perceptions of a partner's response are likely to involve both veridical assessment of the partner's reaction and motivated interpretation (Reis et al., 2004). Although both matter in our model of the capitalization process, the perception of a partner's responsiveness is proximal, whereas the partner's actual response, as well as any dispositional tendencies that influence such perceptions, is more distal. In other words, an enthusiastic response is likely to benefit the recipient only if it is perceived as such (for discussion of this issue, see Drigotas, Rusbult, Wieselquist, \& Whitton, 1999). Thus, Studies 2 and 3 focused on perceptions of a close relationship partner's typical responses to one's attempts at capitalization.
In these studies, we adapted a typology based on Rusbult's model of responses to a partner's negative behavior (e.g., Rusbult, Zembrodt, \& Gunn, 1982). This model, which Rusbult adapted from Hirschman's (1970) work in organizational settings, differentiates responses to a partner's potentially destructive behavior along two dimensions: constructive-destructive and activepassive. Constructive responses to problematic behavior and conflicts may be either active (termed voice; e.g., "he/she talks about what is going on") or passive (termed loyalty; e.g., "he/she gives me the benefit of the doubt and forgets about it"), whereas destructive responses can be active (termed exit; e.g., "he/she considers breaking up") or passive (termed neglect; e.g., "he/she avoids me for awhile"). Rusbult's research on accommodation has shown that both types of constructive responses (voice and loyalty) positively predict relationship well-being, whereas both types of destructive responses (exit and neglect) negatively predict relationship well-being (Rusbult, Verette, Whitney, Slovic, \& Lipkus, 1991). Although sharing positive news about the self does not map perfectly onto accommodation processes, our adaptation of Rusbult's framework is conceptually useful. Thus, in parallel fashion we differentiated active-constructive responses (e.g., enthusiastic support), passive-constructive responses (e.g., quiet, understated support), active-destructive responses (e.g., quashing the event), and passive-destructive responses (e.g., ignoring the event). We predicted that active-constructive responses would be positively associated with the quality of the relationship, whereas passivedestructive and active-destructive responses would be negatively associated with relationship quality. We made no predictions about passive-constructive responses for two reasons. First, in Rusbult's research, loyalty is beneficial presumably because it precludes the added relationship harm engendered by active consideration of conflicts and disagreements. No such benefit would accrue in the case of a positive event. Also, in research using this typology, loyalty has tended to yield somewhat weaker or more inconsistent results than the other three categories.

\section{Study 2 \\ Method}

\section{Participants and Procedure}

Couples who had been dating for a minimum of 3 months were recruited through flyers posted around campus offering $\$ 10$ per couple for participation in a survey. Fifty-nine heterosexual couples who had been dating for an average of 14.0 months $(S D=8.9)$ participated in the study. Both partners participated in the same session but completed the measures independently.

\section{Measures}

Commitment. Relationship commitment was measured with the sevenitem Commitment Scale (Rusbult, Martz, \& Agnew, 1998). Participants responded on a 7-point scale from 1 (not at all true of my relationship) to 7 (very true of my relationship). Sample items include "I want our relationship to last forever" and "It is likely that I will date someone other than

\footnotetext{
${ }^{3}$ Coefficients using the continuous capitalization variable as a predictor of the three outcomes were $b=.09(p<.001)$ for PA, $b=-.01(p=n s)$ for NA, and $b=.09(p<.01)$ for satisfaction with life.
} 
Table 2

Perceived Responses to Capitalization Attempts Scale Items and Subscale Reliabilities (Study 2)

\begin{tabular}{|c|c|c|c|}
\hline \multirow[b]{2}{*}{ Category } & \multirow[b]{2}{*}{ Response } & \multicolumn{2}{|c|}{$\alpha$} \\
\hline & & Male & Female \\
\hline Active-Constructive & $\begin{array}{l}\text { My partner usually reacts to my good fortune enthusiastically. } \\
\text { I sometimes get the sense that my partner is even more happy and excited than I am. } \\
\text { My partner often asks a lot of questions and shows genuine concern about the good event. }\end{array}$ & .74 & .84 \\
\hline Passive-Constructive & $\begin{array}{l}\text { My partner tries not to make a big deal out of it, but is happy for me. } \\
\text { My partner is usually silently supportive of the good things that occur to me. } \\
\text { My partner says little, but I know he/she is happy for me. }\end{array}$ & .66 & .87 \\
\hline Active-Destructive & $\begin{array}{l}\text { My partner often finds a problem with it. } \\
\text { My partner reminds me that most good things have their bad aspects as well. } \\
\text { He/she points out the potential down sides of the good event. }\end{array}$ & .78 & .71 \\
\hline Passive-Destructive & $\begin{array}{l}\text { Sometimes I get the impression that he/she doesn't care much. } \\
\text { My partner doesn't pay much attention to me. } \\
\text { My partner often seems disinterested. }\end{array}$ & .80 & .72 \\
\hline
\end{tabular}

Note. Stem was "When I tell my partner about something good that has happened to me ... "

my partner within the next year" (reversed). The commitment scale was reliable ( $\alpha=.91$ for women and .87 for men).

Satisfaction. Relationship satisfaction was measured with the sevenitem Relationship Assessment Scale (Hendrick, 1988). Participants responded using a 7-point scale with 1 indicating low satisfaction and 7 indicating high satisfaction. Sample items include "How well does your partner meet your needs?" and "How good is your relationship compared to most?" An ambiguity in the response scale for one item ("How much do you love your partner?") lowered the internal consistency of the scale, and so this item was dropped from analyses. Reliability of the remaining six-item scale was adequate ( $\alpha=.68$ for women and .74 for men).

Trust. Trust was measured with a 26-item Trust Scale (Rempel, Holmes, \& Zanna, 1985), which has three subscales: Faith, Dependability, and Predictability. Participants responded on a 7-point scale from 1 (not at all true of my relationship) to 7 (very true of my relationship). Sample items include "Though times may change and the future is uncertain, I know my partner will always be ready and willing to offer me strength and support" (Faith subscale), "I can rely on my partner to keep the promises he/she makes to me" (Dependability subscale), and "I am familiar with the patterns of behavior my partner has established and I can rely on him/her to behave in certain ways" (Predictability subscale). Two items proved to be unreliable ("In general my partner does things in a variety of different ways. He/ she almost never sticks to one way of doing things"; "I am certain that my partner would not cheat on me, even if the opportunity arose and there was no chance that he/she would get caught") for the current sample and were dropped from analyses. The three subscales were positive and significantly correlated with one another and produced a one-factor solution in a principal-components analysis (for both men and women). Therefore, the three subscales were combined into a single measure of trust ( $\alpha=.85$ for women and $\alpha=.88$ for men).

Intimacy. Participants also completed four subscales of Shaefer and Olson's (1981) PAIR intimacy scale: Social, Emotional, Intellectual, and Recreational intimacy (six items each). Items were rated on a 7-point scale from 1 (not at all true of my partner) to 7 (very true of my partner). Sample items include, "My partner can really understand my hurts and joys" (emotional intimacy), "We enjoy spending time with other couples" (social intimacy), "When it comes to having a serious discussion it seems that we have little in common" (intellectual intimacy, reverse scored), and "We enjoy the same recreational activities" (recreational intimacy). Because a principal-components analysis indicated that a one-factor solution was optimal (for both men and women), the four scales were combined into a single scale, with good reliability $(\alpha=.82$ for women and $\alpha=.86$ for men). ${ }^{4}$
Accommodation. Perceptions of partners' response to negative behaviors were assessed with Rusbult et al.'s (1991) 24-item measure of accommodation. The original measure was designed to assess self-reported destructive and constructive tendencies toward responding to one's partner's potentially destructive behavior (e.g., yelling at the participant). In the present study, participants rated 12 items (Rusbult, Johnson, \& Morrow, 1986) that assessed perceptions of the partner's response to one's own negative behavior in four categories: Active-Constructive (voice; e.g., "When I act angry or distant with my partner, he/she talks about what's going on"), Passive-Constructive (loyalty; e.g., "When I act angry or distant with my partner, he/she remains loyal and quietly waits for things to get better"), Active-Destructive (exit; e.g., "When my partner is unhappy with me, he/she considers breaking up."); and Passive-Destructive (neglect; e.g., "When I say or do things my partner doesn't like, he/she avoids me for awhile"). Reliabilities were very good for both men and women ( $\alpha$ s ranged from .79 to .96). Consistent with previous research (Wieselquist, Rusbult, Foster, \& Agnew, 1999), a composite accommodation score was also computed by subtracting the two destructive scales from the two constructive scales.

Perceived Responses to Capitalization Attempts (PRCA) Scale. A new scale, which we refer to as the capitalization scale, was constructed to measure perceptions of partners' responses to the sharing of positive events. We originally developed 26 items and retained the 12 best items on the basis of response range and nonredundancy. The items followed Rusbult et al.'s (1991) two-dimensional framework and are listed in Table 2. The instructions were as follows:

Please take a moment to consider how your partner responds when you tell him or her about something good that has happened to you. For example, imagine that you come home and tell your partner about receiving a promotion at work, having a great conversation with a family member, getting a raise, winning a prize, or doing well on an exam at school or a project at work. Please consider to what extent your partner does the following things in response to your good fortune.

Participants rated each item using the stem, "When I tell my partner about something good that has happened to me ..." using a 7-point scale from 1 (not

${ }^{4}$ The PAIR emotional subscale is similar in its content to the Reis and Shaver (1988) intimacy model that guided this research; the three other subscales are somewhat less germane. However, because of the high correlation among subscales we elected to combine all four into a single overall score. 
Table 3

Correlations of Four Types of Perceived Capitalization Responsiveness and Composite Score With Relationship Quality Variables (Study 2)

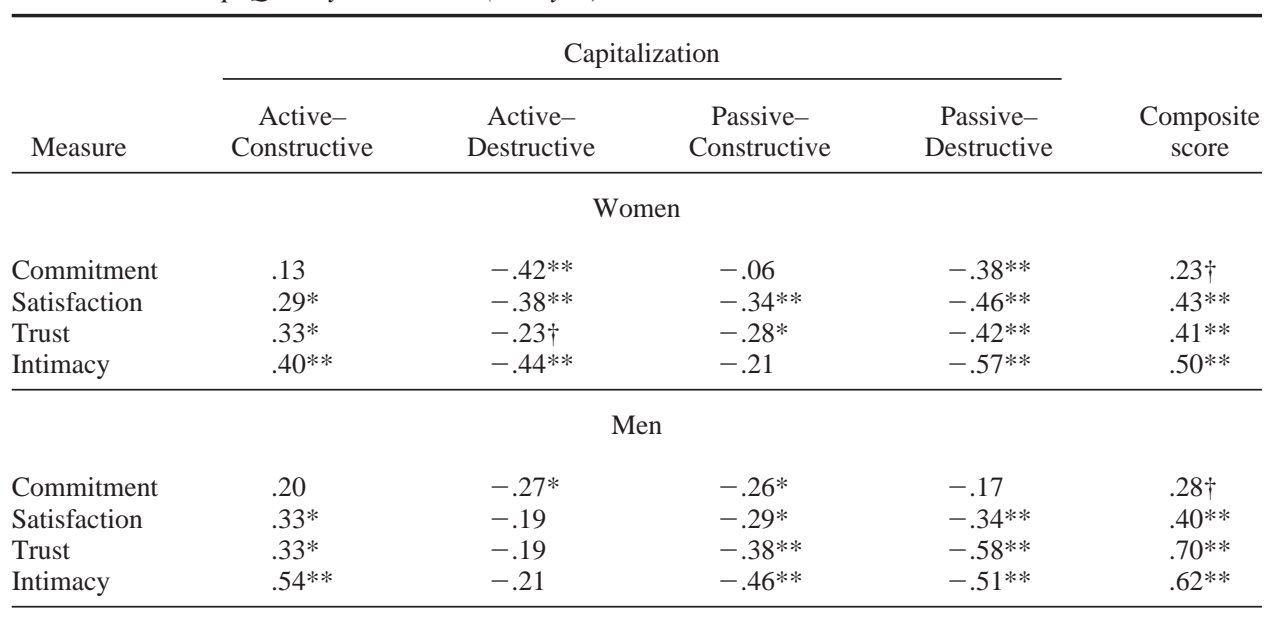

Note. $N=118$ (59 men, 59 women). The composite score was computed by subtracting the ActiveDestructive, Passive-Destructive, and Passive-Constructive scales from the Active-Constructive scale.

$\dagger p<.10 . * p<.05$. *** $p<.01$.

at all true) to 7 (very true). Each subscale showed adequate reliability for both men and women, as shown in Table 2. In addition, paired-samples $t$ tests did not reveal any significant sex differences on the subscales.

\section{Results}

First, we computed correlations between the four types of perceived capitalization responses and the relationship quality variables, separately for men and women. ${ }^{5}$ As shown in Table 3, capitalization responses were associated with relationship quality, and most effects were significant at $p<.05$. The pattern of findings was consistent across measures: Active-Constructive responses were positively correlated with commitment, satisfaction, intimacy, and trust, whereas Passive-Constructive, Active-Destructive, and Passive-Destructive responses were negatively correlated with these measures. These results are consistent with our hypotheses. Also noteworthy is the fact that Passive-Constructive responses, which in accommodation research tend to be associated with desirable outcomes, were herein associated with undesirable outcomes.

To facilitate comparison with research on accommodation, we also computed a composite capitalization score representing favorable responding to capitalization attempts based on the pattern of correlations of the PRCA subscales with the relationship quality measures (this pattern was replicated in Study 3). Because ActiveConstructive responses were positively related to relationship well-being, and the passive-constructive and both types of destructive responses were negatively related to relationship wellbeing, the composite capitalization score was created by subtracting the Passive-Constructive, Active-Destructive, and PassiveDestructive scores from the Active-Constructive score. Thus, higher scores indicated more positive and less negative responses to capitalization attempts. The composite score was significantly correlated with satisfaction, trust, and intimacy for both men and women and marginally correlated with commitment for both men and women (see Table 3).

We also examined correlations between capitalization and ac- commodation, as shown in Table 4. The strength of the association between accommodation and capitalization ranged from .01 to .52. Thus, there was evidence that both measures were partially assessing "good relationship behavior"; however, there was also substantial independence.

Finally, to demonstrate discriminant validity, we sought to determine whether perceived support for capitalization attempts was associated with relationship quality, controlling for perceived responses to negative behavior (accommodation). Partial correlations were computed between the four capitalization scales and the composite score, controlling for perceived accommodation. As Table 5 shows, the associations between capitalization responses and intimacy, trust, and satisfaction remained significant. ${ }^{6}$ It is interesting that none of the capitalization measures predicted trust for women once accommodation was controlled, although they did so for men, quite strongly.

\footnotetext{
${ }^{5}$ We also examined associations between accommodation and four relationship quality measures to confirm that responses to negative behavior were measured adequately. Consistent with prior studies, accommodation significantly predicted commitment, satisfaction, trust, and intimacy for women (.31, $.51, .69$, and .59 , respectively) and for men $(.28, .39, .56$, and .46 , respectively; all $p \mathrm{~s}<.05)$.

${ }^{6}$ Alternative analyses were conducted with couple as the unit of analysis $(n=59)$. Specifically, path models were constructed in which male composite capitalization, female composite capitalization, male composite accommodation, and female composite accommodation scores were upstream variables that were all free to covary. The downstream variables were male and female outcomes (e.g., satisfaction), whose error terms were also permitted to covary. These analyses produced nearly identical results as the partial correlations analyses reported in Table 4; specifically, all significant partial correlations among capitalization and the outcome variables remained significant in the path analyses. Thus, the results in Table 4 remain stable, even when allowing all four predictors to covary, controlling for couple covariation in the outcome variable and using couple as the unit of analysis.
} 
Table 4

Correlations Between Accommodation and Capitalization Measure (Study 2)

\begin{tabular}{|c|c|c|c|c|c|}
\hline \multirow[b]{2}{*}{ Capitalization } & \multicolumn{4}{|c|}{ Accommodation } & \multirow[b]{2}{*}{$\begin{array}{l}\text { Composite } \\
\text { score }\end{array}$} \\
\hline & $\begin{array}{c}\text { Active- } \\
\text { Constructive }\end{array}$ & $\begin{array}{c}\text { Active- } \\
\text { Destructive }\end{array}$ & $\begin{array}{c}\text { Passive- } \\
\text { Constructive }\end{array}$ & $\begin{array}{c}\text { Passive- } \\
\text { Destructive }\end{array}$ & \\
\hline \multicolumn{6}{|c|}{ Women } \\
\hline Active-Constructive & $.36^{* *}$ & $-.25 \dagger$ & .07 & $-.27 *$ & $.35^{* * *}$ \\
\hline Active-Destructive & -.09 & $.34 * *$ & -.03 & $.33 *$ & $-.27 *$ \\
\hline Passive-Constructive & $-.23 \dagger$ & .15 & .11 & $.28 *$ & -.20 \\
\hline Passive-Destructive & $-.29 *$ & $.41 * *$ & .01 & $.45 * *$ & $-.40 * *$ \\
\hline Composite & $.38 * *$ & $-.33^{*}$ & .02 & $-.39 * *$ & $.41^{* *}$ \\
\hline \multicolumn{6}{|c|}{ Men } \\
\hline Active-Constructive & $.52 * *$ & $-.22 \dagger$ & .21 & $-.43 * *$ & $.52 * *$ \\
\hline Active-Destructive & .01 & .22 & .14 & -.07 & .03 \\
\hline Passive-Constructive & -.10 & .04 & .09 & $.26^{*}$ & -.12 \\
\hline Passive-Destructive & -.17 & .14 & .05 & .19 & -.16 \\
\hline Composite & $.43 * *$ & $-.23 \dagger$ & .10 & $-.40 * *$ & $.43^{* *}$ \\
\hline
\end{tabular}

Note. $\quad N=118$ (59 men, 59 women). The composite Accommodation score was computed by subtracting the Active-Destructive and Passive-Destructive scales from the Active-Constructive and Passive-Constructive scales. The composite Capitalization score was computed by subtracting the Active-Destructive, PassiveDestructive, and Passive-Constructive scales from the Active-Constructive scale.

$\dagger p<.10 . \quad * p<.05 . \quad * * p<.01$.

\section{Brief Discussion}

Study 2 showed that perceived responses by a close relationship partner to capitalization attempts were reliably associated with relationship quality. Active-Constructive responses were positively associated with better relationship quality, whereas passiveconstructive and both active- and passive-destructive responses were negatively associated with relationship quality. The finding that passive-constructive responses were negatively associated with relationship quality was noteworthy, both because such responses might have been expected to be beneficial for reasons of face validity and because in accommodation research, this type of response tends to be beneficial. However, only more active and outwardly encouraging responses to the sharing of positive events predicted relationship quality; the less demonstrative form of support did not. We defer discussion of this finding to the General Discussion after examining whether or not it is replicated in a married sample. Finally, although there were few gender differ-

Table 5

Partial Correlations of Four Types of Perceived Capitalization Responsiveness and Composite Score With Relationship Quality Variables Controlling for Accommodation (Study 2)

\begin{tabular}{|c|c|c|c|c|c|}
\hline \multirow[b]{2}{*}{ Measure } & \multicolumn{4}{|c|}{ Capitalization } & \multirow[b]{2}{*}{$\begin{array}{l}\text { Composite } \\
\text { score }\end{array}$} \\
\hline & $\begin{array}{c}\text { Active- } \\
\text { Constructive }\end{array}$ & $\begin{array}{c}\text { Active-- } \\
\text { Destructive }\end{array}$ & $\begin{array}{l}\text { Passive- } \\
\text { Constructive }\end{array}$ & $\begin{array}{c}\text { Passive- } \\
\text { Destructive }\end{array}$ & \\
\hline \multicolumn{6}{|c|}{ Women } \\
\hline Commitment & .03 & $-.37 * *$ & .01 & $-.29 *$ & .12 \\
\hline Satisfaction & .14 & $-.29 *$ & $-.29 *$ & $-.33 *$ & $.29 *$ \\
\hline Trust & .13 & -.07 & -.20 & -.22 & .20 \\
\hline Intimacy & $.27 *$ & $-.36^{* *}$ & -.14 & $-.45^{* *}$ & $.37 * *$ \\
\hline \multicolumn{6}{|c|}{ Men } \\
\hline Commitment & .07 & $-.29 *$ & $-.24 \dagger$ & -.15 & .19 \\
\hline Satisfaction & .17 & $-.22 \dagger$ & $-.27^{*}$ & $-.31 *$ & $.28 *$ \\
\hline Trust & $.52 * *$ & $-.24 \dagger$ & $-.38 * *$ & $-.60 * *$ & $.61 * *$ \\
\hline Intimacy & $.39 * *$ & $-.26 \dagger$ & $-.46^{* *}$ & $-.49 * *$ & $.52 * *$ \\
\hline
\end{tabular}

Note. $N=118$ (59 men, 59 women). The composite score was computed by subtracting the ActiveDestructive, Passive-Destructive, and Passive-Constructive scales from the Active-Constructive scale. $\dagger p<.10 . \quad * p<.05 . \quad * * p<.01$. 
ences, when accommodation was controlled, trust was related to capitalization for men but not for women. Perhaps trust is more closely related to concerns about the responses to the self's negative behaviors among women than among men.

Study 3 was designed to examine the same hypotheses in a community sample of married persons. Also, because all measures in Study 2 were obtained at a single session, Study 3 incorporated measures and procedures to control for the possibility of method and mood artifacts by assessing the predictor and criterion variables at different times and by using daily experience methodology.

\section{Study 3}

\section{Method}

\section{Participants}

Participants in Study 3 were 178 heterosexual married adults (89 couples) from Rochester, New York. Couples were recruited from advertisements in two local newspapers and were paid $\$ 60$ (i.e., $\$ 30$ to each spouse) for their participation. The mean age of participants was 38.1 years $(S D=$ $10.0 ; M d n=37.0$; range 21-73). Couples had been married an average of 10.1 years $(S D=9.6 ; M d n=7.0$; range $1-43)$. It was the first marriage for $75 \%$ of the men and $84 \%$ of the women. The couples had an average of 1.9 children $(S D=1.3)$, of whom an average of $1.5(S D=1.5)$ lived at home.

Participants' personal income ranged from under $\$ 10,000$ to over $\$ 50,000$ : $21.3 \%$ reported less than $\$ 10,000,12.4 \%$ reported $\$ 10,000$ $\$ 20,000,16.9 \%$ reported $\$ 20,000-\$ 30,000,18.0 \%$ reported $\$ 30,000$ $\$ 40,000,9 \%$ reported $\$ 40,000-\$ 50,000,20.2 \%$ reported an income greater than $\$ 50,000$, and $2.2 \%$ did not respond. The sample also encompassed a range of education levels: $2.8 \%$ had less than a high school education, $9.0 \%$ graduated from high school, $33.1 \%$ had some college, $36.5 \%$ had completed college, and $18.5 \%$ had attended graduate school. In terms of current employment status, $60.8 \%$ were employed full time, $18.0 \%$ were employed part time, $10.1 \%$ were full-time homemakers, $3.4 \%$ were unemployed and looking for work, $2.2 \%$ were retired, and $5.1 \%$ were full- or part-time students who were also working full or part time.

\section{Procedure}

Participants who responded to the advertisements were contacted by an experimenter who provided a brief description of the study and scheduled their initial appointments. All 89 couples completed the study. Participants were scheduled for two appointments, approximately 2 weeks apart. After receiving initial instructions in the first session, spouses were led into separate adjoining rooms to complete the initial packet of questionnaires. Spouses had no contact with each other while completing the questionnaires. The packet included questionnaires assessing perceived responses to capitalization attempts, marital satisfaction, and intimacy. After both spouses had completed these measures, they were brought together and given instructions for the daily diaries. The diary record included measures describing their daily interaction with each other and their feelings about their relationship on that day. Participants were asked to complete one diary record each night (beginning that evening) before going to bed. ${ }^{7}$ They returned to the laboratory approximately 2 weeks after their initial appointment to hand in their completed diary forms. Participants handed in an average of 13 completed (out of 14 possible) forms. Participants were then given an additional packet of questionnaires to complete at home and return by mail.

\section{One-Time Measures}

Overall marital satisfaction. Initial overall marital satisfaction was assessed with the five-item Quality Marriage Index (QMI; Norton, 1983) during the first session. Participants responded to each item on a 7-point scale (from strongly disagree to strongly agree), answering questions about how they generally felt about their marriage. This measure showed excellent reliability ( $\alpha=.95$ in the present study).

Intimacy. As in Study 2, intimacy was measured with Shaefer and Olson's (1981) PAIR intimacy scale in the follow-up packet administered after conclusion of the daily experience portion of the study. Seventy-five couples returned completed intimacy scales.

PRCA. Participants completed the same 12-item PRCA measure as in Study 2. Reliability was good for all the subscales for both men and women ( $\alpha$ s ranging from .65 to .83), with the exception of the PassiveConstructive scale for women, which was somewhat lower $(\alpha=.57)$.

\section{Daily Measures}

Daily marital satisfaction. Daily marital satisfaction was assessed with a single item used previously by Gable, Reis, and Downey (2003), asking for an overall rating of the relationship on that day. A 9-point response scale was used, from 1 (Terrible) to 5 (O.K.) to 9 (Terrific). A composite daily marital satisfaction score was computed by averaging across all days for each participant. Average daily satisfaction was $6.4(S D=1.1)$ for men and $6.6(S D=1.1)$ for women. A paired-samples $t$ test showed that this difference was not significant.

Daily conflicts. Each day participants were asked if they had experienced any of the following four types of conflicts: "minor conflicts, resolved"; "minor conflicts, unresolved"; "major conflicts, resolved"; and "major conflicts, unresolved." Husbands and wives agreed on the occurrence (or nonoccurrence) of these events remarkably well; the percentage of agreement was 82, 90, 98, and 97, respectively, for each category. Conflicts were summed across days and categories and then divided by the number of daily reports completed to produce an estimate of total conflict. On average, spouses reported some type of conflict on $21.3 \%$ of days.

Daily positive activities. Participants were asked if they had done anything "relaxing" or "fun" with their spouse on that day. Again, agreement between spouses was high: $76 \%$ for relaxing and $75 \%$ for fun. The number of days on which each type of event was experienced was computed for each participant and then summed to produce an estimate of positive activities across days. On average, spouses reported a positive activity on $40.1 \%$ of days.

\footnotetext{
${ }^{7}$ Participants were given 14 letter-size envelopes, a large envelope, and 14 blank diary forms. They were instructed to place each diary form into a letter envelope and to seal it when completed, both to ensure that each day's report was independent of the previous reports (i.e., to keep them from looking at yesterday's diary to complete today's) and to ensure that each spouse retained confidentiality. Participants were asked to think of a place in their home where they could privately complete their daily forms. Participants then made a verbal commitment to the experimenter and to each other that they would complete the forms independently. They were also given the following instructions: "It is perfectly fine to talk about the types of things on the daily diaries that would normally come up in conversation. We are, however, asking that you not discuss with each other what you wrote down on previous daily diaries, or share your thoughts on how you are planning to complete upcoming diaries. This will allow us to examine each person's responses as separate reports of the day."
} 
Table 6

Correlations of Four Types of Perceived Capitalization Responsiveness and Composite Score With Daily Relationship Quality Variables and Intimacy (Study 3)

\begin{tabular}{|c|c|c|c|c|c|}
\hline \multirow[b]{2}{*}{ Measure } & \multicolumn{4}{|c|}{ Capitalization } & \multirow[b]{2}{*}{$\begin{array}{l}\text { Composite } \\
\text { score }\end{array}$} \\
\hline & $\begin{array}{c}\text { Active- } \\
\text { Constructive }\end{array}$ & $\begin{array}{c}\text { Active- } \\
\text { Destructive }\end{array}$ & $\begin{array}{c}\text { Passive- } \\
\text { Constructive }\end{array}$ & $\begin{array}{c}\text { Passive- } \\
\text { Destructive }\end{array}$ & \\
\hline \multicolumn{6}{|c|}{ Women } \\
\hline Daily satisfaction & $.34 * *$ & $-.18 \dagger$ & $-.34 * *$ & $-.37 * *$ & $.40 * *$ \\
\hline Daily conflicts & $-.32 * *$ & $.34 * *$ & .10 & $.42 * *$ & $-.39 * *$ \\
\hline Daily positive activities & $.21 *$ & .06 & $-.22 *$ & -.17 & $.20 \dagger$ \\
\hline Intimacy & $.43^{* *}$ & -.15 & $-.32 * *$ & $-.35 * *$ & $.45^{* *}$ \\
\hline \multicolumn{6}{|c|}{ Men } \\
\hline Daily satisfaction & $.47 * *$ & $-.33^{* *}$ & $-.23 *$ & $-.45^{* *}$ & $.50^{* *}$ \\
\hline Daily conflicts & $-.22 *$ & .17 & .16 & .14 & $-.23 *$ \\
\hline Daily positive activities & $.20 \dagger$ & $-.23 *$ & -.16 & $-.28 * *$ & $.26^{*}$ \\
\hline Intimacy & $.35 * *$ & $-.23^{*}$ & $-.21 \dagger$ & $-.40 * *$ & $.39 * *$ \\
\hline
\end{tabular}

Note. $\quad N=178$ (89 men, 89 women, except for analyses with intimacy, $n=75$ men, 75 women).

$\dagger p<.10$. * $p<.05$. ** $p<.01$.

\section{Results}

As in Study 2, we first computed correlations between the four types of perceived capitalization responses and relationship outcomes (intimacy and the three aggregated daily relationship variables), separately for men and women. Table 6 shows similar results to Study 2. All four types of capitalization responses were significantly associated with all outcome variables. ActiveConstructive responses were positively correlated with intimacy, daily satisfaction, and daily positive activities and negatively correlated with daily conflicts, whereas Active-Destructive and Passive-Destructive responses were negatively correlated with intimacy, daily satisfaction, and daily positive activities and positively correlated with daily conflicts. Also as in Study 2, PassiveConstructive responses predicted poorer relationship outcomes for both women and men.

We again computed a composite capitalization score representing favorable responding to capitalization attempts by subtracting the Passive-Constructive (because it was negatively related to relationship well-being), Active-Destructive, and PassiveDestructive scores from the Active-Constructive score. Thus, higher scores indicated more positive and less negative responses to capitalization attempts. The composite score, shown in the final column of Table 6, was significantly correlated with intimacy, daily satisfaction, and conflicts, both for husbands and wives. Daily positive activity was significantly correlated with capitalization for men and marginally for women. These findings closely replicate those of Study 2, with the methodologically important addition of two interaction-based variables (conflict and positive activities) and a daily measure of marital satisfaction.

To establish that responses to capitalization attempts were associated with relationship outcomes over and above global positivity (represented here by the QMI measure of marital satisfaction), we computed partial correlations between capitalization and relationship outcomes, controlling for global marital satisfaction, separately for men and women. ${ }^{8}$ As displayed in Table 7 , the association between the PRCA scales and daily satisfaction and intimacy remained significant even when global marital satisfaction was controlled, for both husbands and wives, although two of the correlations for husbands became nonsignificant. For women, all but one of the significant correlations between the PRCA scales and relationship outcomes remained significant when controlling for initial satisfaction (the remaining one was marginally significant). However, among men, the association between capitalization and daily conflicts and daily positive activities became weaker and nonsignificant when global marital satisfaction was controlled. On the whole, these analyses demonstrate that the predictive benefits of capitalization are not artifacts of general positivity (with the exception of the latter result for men).

\section{Brief Discussion}

The findings of Study 3 extended the prior results to a more diverse sample of married persons. Consistent with Study 2, only active-constructive responses were positively associated with better relationship quality; passive-constructive, active-destructive, and passive-destructive responses were negatively associated with relationship quality. The replicated negative correlation for

\footnotetext{
${ }^{8}$ As in Study 2, alternative analyses were also conducted with couple as the unit of analysis $(n=89)$. Path models were constructed in which husbands' capitalization, husbands' initial marital satisfaction, wives' capitalization, and wives' initial marital satisfaction scores were upstream variables that were all free to covary. The downstream variables were husbands' and wives' outcomes (e.g., daily satisfaction), whose error terms were also permitted to covary. These analyses produced nearly identical results as the partial correlations analyses reported in Table 6 . That is, the results in Table 6 remain stable, even when allowing all predictors to covary, controlling for couple covariation in the outcome variable and using couple as the unit of analysis.
} 
Table 7

Partial Correlations of Four Types of Perceived Capitalization Responsiveness and Composite Score With Daily Relationship Quality Variables and Intimacy Controlling for Initial Marital Satisfaction (Study 3)

\begin{tabular}{|c|c|c|c|c|c|}
\hline \multirow[b]{2}{*}{ Measure } & \multicolumn{4}{|c|}{ Capitalization } & \multirow[b]{2}{*}{$\begin{array}{l}\text { Composite } \\
\text { score }\end{array}$} \\
\hline & $\begin{array}{c}\text { Active- } \\
\text { Constructive }\end{array}$ & $\begin{array}{c}\text { Active- } \\
\text { Destructive }\end{array}$ & $\begin{array}{c}\text { Passive- } \\
\text { Constructive }\end{array}$ & $\begin{array}{c}\text { Passive- } \\
\text { Destructive }\end{array}$ & \\
\hline \multicolumn{6}{|c|}{ Women } \\
\hline Daily satisfaction & $.23^{*}$ & -.12 & $-.31 * *$ & $-.26^{*}$ & $.30 * *$ \\
\hline Daily conflicts & $-.27 *$ & $.31 * *$ & .07 & $.38 *$ & $-.34 * *$ \\
\hline Daily positive activities & $.21 \dagger$ & .08 & $-.21 *$ & -.16 & $.20 \dagger$ \\
\hline Intimacy & $.38 * *$ & -.12 & $-.28 *$ & $-.29 *$ & $.40^{* *}$ \\
\hline \multicolumn{6}{|c|}{ Men } \\
\hline Daily satisfaction & $.35 * *$ & $-.21 *$ & -.16 & $-.20 \dagger$ & $.35^{*}$ \\
\hline Daily conflicts & -.10 & .07 & .10 & .09 & -.08 \\
\hline Daily positive activities & .09 & -.15 & -.10 & -.11 & .13 \\
\hline Intimacy & $.27 *$ & -.13 & -.09 & -.19 & $.26^{*}$ \\
\hline
\end{tabular}

Note. $\quad N=178$ (89 men, 89 women, except for analyses with intimacy, $n=75$ men, 75 women).

$\dagger p<.10 . * p<.05$. ** $p<.01$.

passive-constructive responses suggests that despite the positive wording of these items ("My partner says little, but I know he/she is happy for me"), they appear to be associated with detrimental effects. We discuss this result, as well as the clear divergence from published results on the beneficial effects of passive-constructive responses to a partner's bad behavior (accommodation), in the General Discussion.

Studies 2 and 3 demonstrated that perceived responsiveness to capitalization attempts contributes in an important way to relationship quality. Study 4 had two aims. First, we sought to determine whether both independent variables examined in Studies 1-3-that is, the act of sharing positive events (capitalization attempts) with others and their perceived response-have simultaneous intrapersonal benefits (specifically, daily life satisfaction and affect). Second, we sought to evaluate one mechanism (described above) that might be responsible for these effects. That is, because the communicative act is likely to involve retelling, rehearsal, and elaboration, it may increase the event's salience and accessibility in memory, thereby enhancing its impact on ratings of personal well-being. Study 4 therefore examined whether positive events that are communicated to others are remembered better than positive events not communicated to others.

\section{Study 4}

\section{Method}

\section{Participants and Procedure}

Ninety-nine undergraduate participants began Study 4, and 94 (19 men and 75 women) completed a minimum of three daily assessments on time. They received extra credit toward psychology coursework in exchange for participation (ages ranged from 17 to 49 years; $M=20.1, S D=4.4$ ). The sample was ethnically diverse: $1 \%$ of participants were American Indian,
34\% were Asian/Pacific Islanders, 2.2\% were African American, $12 \%$ were Hispanic, $39 \%$ were White, and $12 \%$ self-identified as "other."

At the beginning of the study, participants were given 10 booklets containing the daily measures, one for each night of the week. To bolster and verify compliance with the diary schedule, participants were told to return completed diaries every 3 days to a locked mailbox located outside the laboratory. As an incentive, whenever participants handed in a set of booklets on time, they received a lottery ticket for a cash prize $(\$ 100)$ to be awarded after the study. Participants who did not return their booklets at the designated time were reminded by phone or e-mail. Only booklets returned on time (or on the morning following the reminder) were treated as valid and retained in the data set. Participants completed 895 days on time, an average of 9.5 days per person. Additionally, all participants were asked to return on the day after their final diary (i.e., Day 11) for a second session. During this session, they handed in their last four diaries and were then given a surprise memory test. Five participants were unable to return on Day 11, and therefore only 89 participants completed the memory test.

\section{Measures}

Positive and negative affect. As in Study 1, the PANAS (Watson et al., 1988) was used to measure daily PA and NA

Life satisfaction. Diener's (1996) five-item Satisfaction With Life Scale was used to measure daily life satisfaction, as in Study 1. Participants responded to each item using a 5-point scale (disagree to agree) according to how they felt that day.

Daily positive event and negative event. As in Study 1, participants were asked to briefly describe the "the most important problem or stressful event or issue of the day" and rate how stressful the event was on a 5-point scale. The mean stress rating for negative events was $3.2(S D=1.1)$ Participants were also asked to briefly describe "the most important positive event or issue of the day" and rate how important the positive event was on a 5-point scale. The mean importance rating for positive events was $3.9(S D=1.0)$. For both the positive and negative event, participants were told that the event or issue could be something that happened today, in the past, or that they anticipated happening in the future. 
Capitalization attempts. This measure differed from that used in Study 1. Participants were asked to indicate which (if any) of the following people they had told about their most important positive event on that day: friend, roommate, sibling, parent, romantic partner, or other. From these items, we computed two measures: a dichotomous score of daily event sharing, in which participants received a score of 1 if they had told anyone and a score of 0 if they had told no one, and a frequency score indicating the number of categories of people on the list they told. We also asked participants the extent to which their positive event had been "due to my own efforts" and "due to luck or good fortune" in an attempt to discern whether events capitalized differed from those not capitalized in causal attributions. Events capitalized on did not differ from those that were not capitalized on either dimension ( $p s=.62$ [effort] and .14 [luck]). In addition, participants were asked to report the extent to which they had told another person about their most stressful negative event of the day. Participants were assigned a 1 on this variable if they indicated having shared their negative event with someone and 0 if they did not.

Perceived responses to capitalization attempts. Participants were also asked to indicate which person they had told first. Response to capitalization attempts was measured by asking participants to rate the response of the first person they had told using four items, one each adapted from the four PRCA scales used in Studies 2 and 3. Participants indicated, using 5-point scales, whether the other person "reacted enthusiastically to my good event" (Active-Constructive), "pointed out the potential problems or down sides of the good event" (Active-Destructive), "said little, but I knew he/she was happy for me" (Passive-Constructive), and "seemed disinterested" (Passive-Destructive). As in the prior studies, a composite responsiveness score was computed by subtracting the average of the latter three items from the first item. Higher scores indicated a more positive response to the capitalization attempt.

Memory quiz. When participants returned to the laboratory for the second appointment (scheduled on the day after their final diary) they were given a "pop quiz." They were instructed as follows:

During your 10-day participation in this study, you have written about the most positive events that happened to you each day. We would like you to try to remember as many of the positive events that you described in your diaries as you can. Please list them in the space provided below.

They were also given identical instructions to recall the negative events of their diaries. The order of these two tasks was counterbalanced across participants. Two coders independently compared each participant's list to their 10 diaries to determine whether each day's events had been successfully recalled. The agreement rate was $89.0 \%$; discrepancies were resolved by a third coder.

\section{Results}

Participants shared their positive event with at least one other person on $80.2 \%$ of days. The percentage of days each category of person was a target of capitalization was as follows: friend, 59.4\%; sibling, $16.1 \%$; parent, $27.6 \%$; roommate, $23.7 \%$; romantic partner (if in a relationship) $45.1 \%$; and other, $3.3 \%$. As expected, and as found in Study 1, people were more likely to share positive events that they felt were more important. The average correlation across days between the importance of the event and the number of different targets told was $r=.17(p<.01)$.

The analysis used was similar to Study 1, with days nested within person. A series of three HLM equations (HLMwin v.5.02; Raudenbush et al., 2000; see Equations 1 and 2 from Study 1) was constructed to examine relationships between capitalization and the three outcome variables (PA, NA, and satisfaction), controlling for the importance of the positive event and the stress of the most negative event. As in Study 1, positive and negative event importance scores were centered around the person's mean in each equation. The top half of Table 8 shows the results of the three HLM equations predicting PA, NA and life satisfaction, using the dichotomous capitalization variable. The results of Study 1 were replicated. On days that people shared a positive event with others, they experienced significantly higher PA and life satisfaction, controlling for the importance of the most positive and most negative event of the day. However, NA was not predicted by sharing; the only significant predictor of NA was the stressfulness of the negative event. Next, these analyses were repeated, using number of different targets told about the positive event instead of the dichotomous variable. The results, shown on the bottom half of Table 8 , were very similar. The more different targets participants told about the positive event, the higher their PA and life satisfaction.

Next, we examined whether the perception of a positive response from the first person told about the event accounted for additional variance in PA and satisfaction over and above the mere fact of sharing the news. Two multilevel equations were computed, in which the outcome (PA or satisfaction) was predicted from positive event importance, the dichotomous capitalization variable, and the composite perceived responsiveness variable. Both event importance and perceived responsiveness were centered around the person's mean. As shown in Table 9, over and above the effects of having told someone else, the more Active-Constructive the perceived response of the first person told, the higher the participant's positive affect and satisfaction with life.

To determine whether any one type of response was more strongly associated with changes in mood and life satisfaction, we also examined the four types of responses, using multilevel equations akin to those described above, substituting each separate item

Table 8

Capitalization and Daily Positive Affect (PA), Negative Affect

(NA), and Satisfaction with Life: Unstandardized HLM

Coefficients (Study 4)

\begin{tabular}{cccc}
\hline & \multicolumn{3}{c}{ Outcome } \\
\cline { 2 - 4 } Predictor & PA & NA & Satisfaction \\
\hline
\end{tabular}

Using dichotomous capitalization variable representing whether or not participant shared the occurrence of the positive event with someone

$\begin{array}{llll}\text { Negative event importance } & -.09 * * & .23 * * & -.21 * * \\ \text { Positive event importance } & .12^{* *} & -.03 \dagger & .22^{* *} * \\ \text { Capitalization: Yes or no } & .16^{*} & -.01 & .14 *\end{array}$

Using no. of people told as capitalization variable representing whether or not participant shared the occurrence of the positive event with someone

Negative event importance Positive event importance

$\begin{array}{rcr}-.10 * * & .22 * * & -.21 * * \\ .11 * * & -.03 \dagger & .21 * * \\ .07 * * & .01 & .07 *\end{array}$

Note. $\quad N=94$. HLM $=$ hierarchical linear modeling; CAPTOT $=$ categories of people on the list told.

$\dagger p<.10 . *{ }^{*} p<.05$. *** $p<.01$ 
for the composite score. Results showed that the activeconstructive response had a significant, positive relationship with PA (unstandardized $b=.06, p<.01$ ) and life satisfaction $(b=$ $.11, p<.001)$, whereas the passive-destructive response had a significant and negative correlation with PA $(b=-.07, p<.05)$ and life satisfaction $(b=-.12, p<.01)$. Thus, in terms of the responsiveness of the first person to whom a capitalization attempt was made, the primary determinant of PA and satisfaction was the degree that the person was enthusiastic and not disinterested. It is interesting to note that passive-destructive responses were also significantly and positively related to daily NA $(b=.06, p<.05)$. In other words, although the daily effect of capitalization per se was confined to changes in PA and life satisfaction and had no influence on NA, a passive-destructive response from the first person told was associated with increased NA. Neither the activedestructive nor the passive-constructive items significantly predicted daily PA, life satisfaction, or NA.

To test our memorability hypothesis, we conducted analyses examining whether capitalizing on positive events and telling people about the negative events would increase memory for these events. On average, participants recalled $58.9 \%$ of their positive events and $51.9 \%$ of their negative events. We predicted that communicating a positive event to others would increase memory for the positive event but that telling people about a negative event would have no effect on memorability. To conduct these analyses, we constructed nonlinear equations using the Bernouli model for dichotomous outcomes (event recalled or event not recalled) option in HLM. ${ }^{9}$ Positive event recall was predicted from the importance of the positive event and the number of people told about the event (group-mean centered), whereas negative event recall was predicted from the stressfulness of the event and the extent to which others were told about the event (group-mean centered). Results of these analyses are shown in Table 10. As predicted, for both types of events, the more important or stressful the event, the more likely it was to be remembered. However, for positive events, the number of people told (a component of the capitalization process) also significantly predicted recall, after controlling for the initial rating of the importance of the event. In contrast, telling others about a negative event did not affect recall significantly.

Table 9

Perceived Responsiveness of Other on Days Capitalized and Daily Positive Affect (PA) and Satisfaction with Life: Unstandardized HLM Coefficients (Study 4)

\begin{tabular}{clc}
\hline & \multicolumn{2}{c}{ Outcome } \\
\cline { 2 - 3 } \multicolumn{1}{c}{ Predictor } & PA & Satisfaction \\
\hline Positive event importance & $.11^{* *}$ & $.21^{* *}$ \\
Capitalization: Yes or no & $.17^{* *}$ & $.18^{* *}$ \\
Perceived responsiveness & $.04^{*}$ & $.08^{* *}$ \\
\hline
\end{tabular}

Note. $\quad N=94$. Perceived responsiveness $=$ total perceived capitalization (i.e., average of active-destructive, passive-destructive, and passiveconstructive subtracted from active-constructive response rating). HLM = hierarchical linear modeling.

$* p<.05 . \quad * * p<.01$.
Table 10

Recall of Events Predicted From Event Importance and Sharing It With Others: Unstandardized HLM Coefficients (Study 4)

\begin{tabular}{llc}
\hline & \multicolumn{2}{c}{ Event type } \\
\cline { 2 - 3 } \multicolumn{1}{c}{ Predictor } & Positive & Negative \\
\hline Event importance-stressfulness & $.41^{* *}$ & $.42^{* *}$ \\
Capitalization-telling others & $.19^{*}$ & .08
\end{tabular}

Note. $\quad N=89$. Predictors for positive event recall were importance ratings and number of people told. Predictors for negative event recall were stressfulness ratings and extent others were told about event. Nonlinear model with logit link function (unit-specific model), all effects fixed. HLM $=$ hierarchical linear modeling.

$* p<.05 . \quad * * p<.01$

\section{Brief Discussion}

Study 4 was designed to test the hypothesis that the intrapersonal benefits of sharing a positive event with others are enhanced when the other's response is perceived to be active and constructive (and not passive or destructive). The findings supported this hypothesis, thereby replicating and extending the findings of Study 1: On days people communicated their positive events to others, they experienced greater positive affect and satisfaction with life, above and beyond the importance of the event itself. Moreover, the more different targets they told, the greater the increase. Second, consistent with Studies 2 and 3, when the first person told was perceived to react in an active-constructive manner (and not in a passive-destructive way), the benefits of capitalization were even greater. Finally, we found support for one possible mechanism in the link between capitalization and well-being: Positive events but not negative events that were shared with others were more likely to be recalled at the end of the study.

\section{General Discussion}

Responses to the occurrence of positive events have received relatively little attention in the literature, perhaps in part because of the belief that "bad is stronger than good" (Baumeister, Bratslavsky, Finkenauer, \& Vohs, 2001) and also because they are seen as less relevant to health and well-being than negative events are. To be sure, important insights about stress, coping, and health have come from research programs that investigate the impact of, and responses to, negative events and stressors (e.g., Taylor, 1991). Nevertheless, it seems an unspoken (or more precisely, unwritten) and underexamined assumption of the literature that positive events, if and when they do occur, have relatively limited impact on individual well-being and interpersonal life. Research (e.g., Diener, Suh, Lucas, \& Smith, 1999) and experience suggest otherwise, however. People commemorate the milestones in their

\footnotetext{
${ }^{9}$ Because of the sample size for the recall analyses (847 days, 89 participants), which was small for conducting nonlinear, Bernouli analyses in HLM, all random effects in the equation were set to zero to ensure convergence. The analyses were also repeated using traditional logit regression techniques, which require smaller samples, and identical results were obtained.
} 
lives, such as marriages, births, and graduations, by sharing them with others, and they mark the yearly passing of these events with announcements, parties, and reunions, often capturing these joyous moments on film or video for later reliving. Indeed, when good fortune knocks, the first response is often to contact significant others to share the news. We suggest that the sharing of good news provides one vehicle by which positive events contribute to individual well-being. We also suggest that understanding of the social sharing of positive events can provide an important complement to existing research on the social sharing of distress.

Our results show that capitalizing on good fortune may have important intrapersonal and interpersonal benefits. Four studies demonstrated that telling others about positive events was associated with higher positive affect and greater life satisfaction. Apparently, this is a common process-people do it often-and the benefits were observed with events that varied greatly in terms of both subjective and objective importance. Furthermore, the wider the net of sharing, the greater the benefits reaped. This research also examined how the response to capitalization attempts influences well-being, finding that active and constructive responses from others, as opposed to passive or destructive responses, were associated with increased benefits, above and beyond the effects of sharing the news itself. We also found interpersonal benefits of capitalization. Perceiving that a close relationship partner tends to respond in an active and constructive manner was associated with higher relationship quality, particularly intimacy. Finally, we found evidence for one possible mechanism for these effects: increased memory for the positive events on which participants capitalized.

Part of the rationale for examining processes related to the sharing of positive events independent of parallel processes related to negative events is that these two sets of processes are likely to be functionally independent (Cacioppo, Gardner, \& Berntson, 1997). Although capitalization was associated with positive affect and life satisfaction, it shared little variance with negative affect, a degree of specificity that is consistent with previous research that has found associations between positive event occurrence and positive affect but not negative affect (e.g., David et al., 1997; Gable et al., 2000). Findings such as these are consistent with theories that posit the existence of two distinct systems, one designed to respond to appetitive stimuli and one designed to respond to aversive stimuli (e.g., Cacioppo et al., 1997; Carver, 1996; Davidson, 1992; Gable \& Reis, 2001; Higgins, 1997). These theories argue that the occurrence of positive events activates the appetitive system, which then regulates the individual's response but not the functionally independent aversive system (which is instead activated by negative events). Although our studies did not address the relation between capitalization and long-term health and well-being, there is suggestive evidence that the appetitive system has important consequences. Particularly relevant to the present research are studies showing the benefits of expressing positive emotions. For example, the expression of positive emotions has been linked to health and well-being (e.g., Harker \& Keltner, 2001). Labott, Ahleman, Wolever, and Martin (1990) found that when participants watched a happy video their immune system showed increased activity, but only when they had been instructed to express their emotions. Our research showed that the sharing of good news was linked to affective benefits beyond the event itself, although we did not ask whether or not participants expressed or withheld their positive feelings. Presumably, the former is more common in natural life; more research is needed to determine whether positive events shared without emotional expression have the same degree of impact.

Our results provide evidence for one mechanism that may contribute to Fredrickson's (1998) broaden-and-build model of positive emotions. The occurrence of positive events typically generates positive emotions, which in turn may help build social resources through shared positive experience. There are several possible reasons why. First, by communicating a positive event, one is in essence displaying one's assets and thus might be seen by others as having greater social capital, and, when others respond benevolently, relationship well-being may be enhanced, strengthening the social bond. Another plausible explanation is that sharing the event with others allows one to relive the experience to some extent, which may be part of the upward spiral to well-being described by Fredrickson and Joiner (2002).

Still another explanation is more emotion specific. Fredrickson's $(1998,2001)$ model is not concerned so much with generalized positive affect, but rather it provides a framework for specific effects of specific positive emotions. Which specific positive emotion is likely to be most closely associated with capitalization? We offer pride as one prospect. Lazarus (1994) defined pride as "enhancement of one's own ego-identity by taking credit for a valued object or achievement; one's own or that of someone or group with whom one identifies" (p. 164). Tangney and Fischer (1995) defined pride as a self-conscious emotion that reflects on one's own doing. In addition to enhancing one's own valuing of personal events or achievements through the process of reflected appraisal, pride may also engender engagement and a sense of connection with others. Consistent with this possibility, post hoc analyses in Study 1 showed a significant partial correlation between the sharing of positive events and pride $(p<.01)$ when controlling for event importance and a sum score of the nine other positive emotions in the PANAS PA scale. In contrast, the partial correlation between capitalization and the sum of these other nine positive emotions was not significant $(p>.35)$ when controlling for pride and event importance. This finding suggests that pride may serve an important social engagement function and may be a fruitful focus for future research. Also, recent research by Emmons and McCullough (2003) has suggested that expressing gratitude for life's blessings is associated with well-being, another possible mediating mechanism that should be explored in future research.

Capitalizing on positive events may have different consequences and mediating mechanisms when the motive underlying the act of sharing differs. For example, positive events may be communicated to share the joy with another, to make a good impression, to establish credibility, to elicit validation, or to increase personal understanding of the event. The interpersonal and intrapersonal benefits of such communications seem likely to depend on the individual's motive; similarly, the underlying mechanisms for these consequences will vary accordingly. This differentiation is evident in Tesser's (2000) self-evaluation maintenance model, which posits differential processes of reflection ("basking in reflected glory") and comparison (i.e., envy) depending on the individual's relationship with the partner and the self-relevance of the event (Beach \& Tesser, 1995; Tesser et al., 1988). Future 
research might focus on the role of motives for disclosure, relationship to target, and event self-relevance in capitalization.

One mechanism for the link between capitalization and wellbeing may involve memory. We found that the act of talking about a positive event with others was associated with better memory for that event. If sharing good fortune renders the event more accessible in memory, not to mention better appreciated, it would be more likely to be recalled at a later time and thereby may have a positive effect on well-being (particularly when it might help buffer the effect of negative events). We found no evidence that sharing negative events with others rendered those events any more salient, possibly because sharing of negative events is intended to help the individual minimize or "get past" the event (i.e., make it less salient) through catharsis or social support. Although we did not see a negative correlation between sharing negative events and recall, future research might focus on the effectiveness of the support provided as a predictor of recall.

Just how the act of telling others about a positive event actually enhances memorability is an open question, but likely candidates include two sorts of processes: those associated with the act of telling (e.g., repetition, elaboration) and those associated with the listener's response. If social support and reassurance helps people downplay the gravity of negative events, enthusiastic responses by others may highlight and emphasize the implications of a positive event, thereby adding to its value and memorability. A somewhat different explanation is that social interaction increases the memorability of information by providing a new memory trace related to the interaction in which the event was recounted.

Three of the four studies in this article provide evidence that responses from others perceived to be active and constructive were associated with emotional well-being and better relationship quality, whereas responses perceived to be destructive or passive were negatively associated with these outcomes. Study 4 also shows that in particular, active-constructive or passive-destructive responses from the first person told had particularly strong links to wellbeing. Because $98 \%$ of capitalization attempts in that study were directed at close others (e.g., friends, roommates, parents, romantic partners), it is possible that the type of response from close others is particularly important. We had hypothesized that destructive responses would undermine well-being and relationship healthafter all, such responses both rebuff the attempt to generate pride and engagement while dampening feelings about the event and the relationship with the target. We did not offer a strong prediction about passive-constructive responses, which, in all three studies, were associated with poorer intrapersonal and interpersonal outcomes.

Passive-constructive responses ("I know my partner is pleased for me even if he/she does not show it") may fail to convey genuine appreciation for several reasons: They may signify that the target in actuality does not much value the event in question; they may indicate the target's disinterest in the relationship; or they may signify jealousy or self-absorption. Any of these would interfere with one's ability to derive additional benefit from the positive emotional responses of a partner. Active and constructive responses to capitalization attempts, on the other hand, directly convey positive information both about the event itself and about the target's feelings about the relationship with the capitalizer: that the capitalizer is understood, valued, and cared for (Reis \& Patrick,
1996; Reis \& Shaver, 1988), affording an opportunity for intimacy. Finally, Higgins (1997) has noted that pain may result from either punishment or nonreward. It seems likely that passiveconstructive responses would be experienced as instances of nonreward, especially because potential capitalizers seem likely to expect a more enthusiastic response. If capitalizing on positive events is truly an appetitive-system process, then not receiving the reward of an enthusiastic response is exactly what would constitute a poor response. Of course, both types of destructive responses are punishing, and only active-constructive responses are rewarding.

Our studies did not allow us to determine whether responses perceived to be passive-constructive differ from those perceived to be active-constructive or passive-destructive. Although prior research has suggested that there is usually a "reality component" to these perceptions (Reis et al., 2004)_perhaps for reasons of jealousy, disinterest, or disengagement-research has also established the existence of motivated misperception. Thus, the perception of an active-constructive and passive-constructive response might follow from differences in expectations, dispositionally based needs for approval, or the current status of the relationship (i.e., similar to research showing that in distressed relationships, a partner's positive behavior may be attributionally discounted (e.g., Fincham, 1985). Similarly, passive-destructive and passiveconstructive responses might differ in that the latter, whether intentionally or outside of awareness, represent the capitalizer's attempt to put a positive spin on the target's perceived-to-be-lessthan-enthusiastic reaction to one's good news. ${ }^{10}$ Our data suggest that the target's response has negative consequences for the discloser, despite his or her seemingly benevolent interpretation. Thus, only active-constructive responses prompt the upward spiral of intra- and interpersonal benefits discussed above. Research is needed to compare these alternatives.

Although this latter finding may at first glance seem inconsistent with Rusbult et al.'s (1991) work on accommodation processes, in which the perception of a passive-constructive response to conflict and bad relationship behavior was associated with better relationship well-being, it should be noted that the kind of behavior we studied is not directly comparable to the kind of behavior studied in accommodation research. Our research concerned responses to one's personal good fortune, which is not directly parallel to bad behavior directed at the partner (although, to be sure, we found that typical capitalization and accommodation styles were modestly associated; see Table 4). A more direct comparison may involve the sharing of personal misfortune, such as is studied in the social support literature. Nevertheless, there is an important parallel in that in both cases, the partner's response is seen as disengaged but putatively positive. Thus, this response style may interact with situational content in an important way: Whereas setting aside the natural reflex to retaliate to a partner's bad behavior may be beneficial, withholding an actively positive response to good news, even if the other "knows" that one is pleased, appears not to be salubrious. In other words, part of the motivation of sharing personal good news may be precisely to elicit active engagement and enthusiasm (and not just positivity) from the other. As part of the important trend in recent years to

\footnotetext{
${ }^{10}$ We thank an anonymous reviewer for these insights.
} 
document and better understand the operation of positive social psychological processes, it will be important to evaluate these alternatives in future research.

We highlight three caveats with regard to our data. First, we focused on the participant's perception of the partner's response without examining interaction directly or how the partner felt about those same responses. It will be important, of course, to directly compare these perspectives in subsequent studies. Regardless of how such studies turn out, however, the potential capitalizer's perception of the partner's response is conceptually and empirically important as a proximal predictor of subsequent affect and behavior. After all, as numerous studies have shown, responsiveness reflects not only real behavior but also the eye of the beholder (for a summary, see Reis et al., 2004). Responses that are intended to be enthusiastic but that are not received as such are very unlikely to be beneficial. This is consistent with recent findings by Gable et al. (2003), who found that when participants reported enacting positive behaviors toward their partner (e.g., giving a compliment), but the intended target failed to recognize the behavior, the behavior had no influence on the intended target's daily mood. A second caveat concerns Studies 2 and 3, in which data on well-being and partner responsiveness were collected concurrently. We are unable to ascertain whether perceived responsiveness leads to relationship well-being, if relationship health leads to greater perceived responsiveness, or both. Finally it should also be noted here that the diary studies were correlational in nature and may confound the impact of the event and the sharing of the event in our daily measurement, particularly to the extent that these processes occurred in rapid succession (i.e., calling a friend immediately after getting good news).

\section{Concluding Comments}

Contemporary psychological research has been criticized for emphasizing misfortune and distress to the exclusion of the positive side of human existence. Good happens, and when it does, people often seek to share the news with their partners and friends. The process of capitalization is central to understanding how people "cope" with positive events, cultivate positive emotions, and enhance social bonds. We believe that capitalization is a fruitful area for theory and research. Further work is needed to identify additional mediators and consequences, individual differences in capitalization seeking and the ability to benefit from capitalization, and the relationship context in which capitalization attempts are likely to be fruitful or counterproductive. Capitalization research may also provide perspective on our understanding of how people cope when things go wrong, in the sense that the intrapersonal benefits of capitalization may help build a firm interpersonal and intrapersonal foundation for coping with the inevitable stressors and conflicts of life.

\section{References}

Aron, A., Aron, E. N., Tudor, M., \& Nelson, G. (1991). Close relationships as including other in the self. Journal of Personality and Social Psychology, 60, 241-253.

Baumeister, R. F. (1998). The self. In D. T. Gilbert, S. T. Fiske, \& G. Lindzey (Eds.), Handbook of social psychology (4th ed., pp. 680-740). New York: Random House.
Baumeister, R. F., Bratslavsky, E., Finkenauer, C., \& Vohs, K. D. (2001) Bad is stronger than good. Review of General Psychology, 5, 323-370.

Beach, S. R. H., \& Tesser, A. (1995). Self-esteem and the extended self-evaluation maintenance model: The self in social context. In M. H. Kernis (Ed.), Efficacy, agency, and self-esteem (pp. 145-170). New York: Plenum Press.

Bolger, N. (1990). Coping as a personality process: A prospective study. Journal of Personality and Social Psychology, 59, 525-537.

Bolger, N., \& Eckenrode, J. (1991). Social relationships, personality, and anxiety during a major stressful event. Journal of Personality and Social Psychology, 61, 440-449.

Bryant, F. B. (1989). A four-factor model of perceived control: Avoiding, coping, obtaining, and savoring. Journal of Personality, 57, 773-797.

Cacioppo, J. T., \& Gardner, W. L. (1999). Emotions. Annual Review of Psychology, 50, 191-214.

Cacioppo, J. T., Gardner, W. L., \& Berntson, G. G. (1997). Beyond bipolar conceptualizations and measures: The case of attitudes and evaluative space. Personality and Social Psychology Review, 1, 3-25.

Carver, C. S. (1996). Emergent integration in contemporary personality psychology. Journal of Research in Personality, 30, 319-334.

Carver, C. S., \& Scheier, M. F. (1994). Situational coping and coping dispositions in a stressful transaction. Journal of Personality and Social Psychology, 66, 184-195.

Cialdini, R. B., Borden, R. J., Thorne, A., Walker, M. R., Freeman, S., \& Sloan, L. R. (1976). Basking in reflected glory: Three (football) field studies. Journal of Personality and Social Psychology, 34, 366-375.

Clark, L. A., \& Watson, D. (1988). Mood and the mundane: Relations between daily life events and self-reported mood. Journal of Personality and Social Psychology, 54, 296-308.

Clark, M. S., Fitness, J., \& Brissette, I. (2001). Understanding people's relationships is crucial to understanding their emotional lives. In G. J. Fletcher \& M. S. Clark (Eds.), Blackwell handbook of social psychology: Interpersonal processes (pp. 253-278). London: Blackwell.

Cohen, S., \& Wills, T. A. (1985). Stress, social support, and the buffering hypothesis. Psychological Bulletin, 98, 310-357.

Cunningham, M. R., \& Barbee, A. P. (2000). Social support. In C. Hendrick \& S. S. Hendrick (Eds.), Close relationships: A sourcebook (pp. 273-285). Thousand Oaks, CA: Sage.

Danner, D. D., Snowdon, D. A., \& Friesen, W. V. (2001). Positive emotions in early life and longevity: Findings from the nun study. Journal of Personality and Social Psychology, 80, 804-813.

David, J. P., Green, P. J., Martin, R., \& Suls, J. (1997). Differential roles of neuroticism, extraversion, and event desirability for mood in daily life: An integrative model of top-down and bottom-up influences. Journal of Personality and Social Psychology, 73, 149-159.

Davidson, R. J. (1992). Emotion and affective style: Hemispheric substrates. Psychological Science, 3, 39-43.

Diener, E. (1996). Traits can be powerful, but are not enough: Lessons from subjective well-being. Journal of Research in Personality, 30, 389-399.

Diener, E., Suh, E. M., Lucas, R. E., \& Smith, H. L. (1999). Subjective well-being: Three decades of progress. Psychological Bulletin, 125, 276-302.

Downey, G., Freitas, A. L., Michaelis, B., \& Khouri, H. (1998). The self-fulfilling prophecy in close relationships: Rejection sensitivity and rejection by romantic partners. Journal of Personality and Social Psychology, 75, 545-560.

Drigotas, S. M., Rusbult, C. E., Wieselquist, J., \& Whitton, S. W. (1999). Close partner as sculptor of the ideal self: Behavioral affirmation and the Michelangelo phenomenon. Journal of Personality and Social Psychology, 77, 293-323.

Emmons, R. A., \& McCullough, M. E. (2003). Counting blessings versus 
burdens: An experimental investigation of gratitude and subjective wellbeing. Journal of Personality and Social Psychology, 84, 377-389.

Eysenck, S. B., Eysenck, H. J., \& Barrett, P. (1985). A revised version of the Psychoticism scale. Personality and Individual Differences, 6, 2129.

Fincham, F. D. (1985). Attribution processes in distressed and nondistressed couples: Responsibility for marital problems. Journal of Abnormal Psychology, 94, 183-190.

Folkman, S., Lazarus, R. S., Dunkel-Schetter, C., Delongis, A., \& Gruen, R. J. (1986). Dynamics of a stressful encounter: Cognitive appraisal, coping, and encounter outcomes. Journal of Personality and Social Psychology, 50, 992-1003.

Fredrickson, B. L. (1998). What good are positive emotions? Review of General Psychology, 2, 300-319.

Fredrickson, B. L. (2001). The role of positive emotions in positive psychology: The broaden-and-build theory of positive emotions. American Psychologist, 56, 218-226.

Fredrickson, B. L., \& Branigan, C. (2001). Positive emotions. In T. J. Mayne \& G. A. Bonanno (Eds.), Emotions: Current issues and future directions. Emotions and social behavior (pp. 123-151). New York: Guilford Press.

Fredrickson, B. L., \& Joiner, T. (2002). Positive emotions trigger upward spirals toward emotional well-being. Psychological Science, 13, 172175.

Gable, S. L. (2000). Appetitive and aversive social motivation. Unpublished doctoral dissertation, University of Rochester, Rochester, NY.

Gable, S. L., \& Reis, H. T. (2001). Appetitive and aversive social interaction. In J. Harvey \& A. Wenzel (Eds.), Close romantic relationships: Maintenance and enhancement (pp. 169-194). Mahwah, NJ: Erlbaum.

Gable, S. L., Reis, H. T., \& Downey, G. (2003). He said, she said: A quasi-signal detection analysis of spouses' perceptions of everyday interactions. Psychological Science, 14, 100-105.

Gable, S. L., Reis, H. T., \& Elliot, A. J. (2000). Behavioral activation and inhibition in everyday life. Journal of Personality and Social Psychology, 78, 1135-1149.

Harker, L., \& Keltner, D. (2001). Expressions of positive emotion in women's college yearbook pictures and their relationship to personality and life outcomes across adulthood. Journal of Personality and Social Psychology, 80, 112-124.

Harlow, R. E., \& Cantor, N. (1995). To whom do people turn when things go poorly? Task orientation and functional social contacts. Journal of Personality and Social Psychology, 69, 329-340.

Hatfield, E., Cacioppo, J. T., \& Rapson, R. L. (1994). Emotional contagion. New York: Cambridge University Press.

Hendrick, S. S. (1988). A generic measure of relationship satisfaction. Journal of Marriage and the Family, 50, 93-98.

Higgins, E. T. (1997). Beyond pleasure and pain. American Psychologist, 52, $1280-1300$.

Hirschman, A. O. (1970). Exit, voice, and loyalty: Responses to decline in firms, organizations, and states. Cambridge, MA: Harvard University Press.

Hobfoll, S. E. (1998). Stress, culture, and community: The psychology and philosophy of stress. New York: Plenum Press.

Labott, S. M., Ahleman, S., Wolever, M. E., \& Martin, R. B. (1990). The physiological and psychological effects of the expression and inhibition of emotion. Behavioral Medicine, 16, 182-189.

Langston, C. A. (1994). Capitalizing on and coping with daily-life events: Expressive responses to positive events. Journal of Personality and Social Psychology, 67, 1112-1125.

Lazarus, R. S. (1991). Cognition and motivation in emotion. American Psychologist, 46, 352-367.

Lazarus, R. (1994). Universal antecedents of emotions. In P. Ekman \& R. J.
Davidson (Eds.), The nature of emotion (pp. 163-171). New York: Cambridge University Press.

Leary, M., \& Baumeister, R. (2000). The nature and function of selfesteem: Sociometer theory. In M. P. Zanna (Ed.), Advances in experimental social psychology (Vol. 32, pp. 1-62). San Diego, CA: Academic Press.

Lewinsohn, P. M., \& Graf, M. (1973). Pleasant activities and depression. Journal of Consulting and Clinical Psychology, 41, 261-268.

Mikulincer, M., \& Shaver, P. R. (2003). The attachment behavioral system in adulthood: Activation, psychodynamics, and interpersonal processes. In M. P. Zanna (Ed.), Advances in experimental social psychology (Vol. 35, pp. 52-153). New York: Academic Press.

Murray, S. L., \& Holmes, J. G. (1993). Seeing virtues in faults: Negativity and the transformation of interpersonal narratives in close relationships. Journal of Personality and Social Psychology, 65, 707-722.

Nezlek, J. B., \& Gable, S. L. (2001). Depression as a moderator of relationships between positive daily events and day-to-day psychological adjustment. Personality and Social Psychology Bulletin, 27, 16921704.

Nolen-Hoeksema, S. (1996). Chewing the cud and other ruminations. In R. S. Wyer Jr. (Ed.), Ruminative thoughts (pp. 135-144). Hillsdale, NJ: Erlbaum.

Nolen-Hoeksema, S. (1998). The other end of the continuum: The costs of rumination. Psychological Inquiry, 9, 216-219.

Norton, R. (1983). Measuring marital quality: A critical look at the dependent variable. Journal of Marriage and the Family, 45, 141-151.

Pettit, J. W., Kline, J. P., Gencoz, T., \& Gencoz, F. (2001). Are happy people healthier? The specific role of positive affect in predicting self-reported health symptoms. Journal of Research in Personality, 35, $521-536$.

Raudenbush, S. W., Bryk, A. S., Cheong, Y. F., \& Congdon, R. T. (2000). HLM 5: Hierarchical linear and nonlinear modeling [Computer software]. Chicago: Scientific Software International.

Reis, H. T., Clark, M. S., \& Holmes, J. G. (2004). Perceived partner responsiveness as an organizing construct in the study of closeness and intimacy. In D. J. Mashek \& A. Aron (Eds.), Handbook of closeness and intimacy (pp. 201-225). Mahwah, NJ: Erlbaum.

Reis, H. T., \& Gable, S. L. (2003). Toward a positive psychology of relationships. In C. L. Keyes \& J. Haidt (Eds.), Flourishing: The positive person and the good life (pp. 129-159). Washington, DC: American Psychological Association.

Reis, H. T., \& Patrick, B. C. (1996). Attachment and intimacy: Component processes. In E. T. Higgins \& A. W. Kruglanski (Eds.), Social psychology: Handbook of basic principles (pp. 523-563). New York: Guilford Press.

Reis, H. T., \& Shaver, P. (1988). Intimacy as an interpersonal process. In S. Duck \& D. F. Hay (Eds.), Handbook of personal relationships: Theory, research, and interventions (pp. 367-389). New York: Wiley.

Rempel, J. K., Holmes, J. G., \& Zanna, M. P. (1985). Trust in close relationships. Journal of Personality and Social Psychology, 49, 95-112.

Rusbult, C. E., Johnson, D. J., \& Morrow, G. D. (1986). Determinants and consequences of exit, voice, loyalty, and neglect: Responses to dissatisfaction in adult romantic involvements. Human Relations, 39, 45-63.

Rusbult, C. E., Martz, J. M., \& Agnew, C. R. (1998). The Investment Model Scale: Measuring commitment level, satisfaction level, quality of alternatives, and investment size. Personal Relationships, 5, 357-391.

Rusbult, C. E., Olsen, N., Davis, J. L., \& Hannon, P. A. (2001). Commitment and relationship maintenance mechanisms. In J. Harvey \& A. Wenzel (Eds.), Close romantic relationships: Maintenance and enhancement (pp. 87-113). Mahwah, NJ: Erlbaum.

Rusbult, C. E., Verette, J., Whitney, G. A., Slovic, L. F., \& Lipkus, I. (1991). Accommodation processes in close relationships: Theory and 
preliminary empirical evidence. Journal of Personality and Social Psychology, 60, 53-78.

Rusbult, C. E., Zembrodt, I. M., \& Gunn, L. K. (1982). Exit, voice, loyalty, and neglect: Responses to dissatisfaction in romantic involvements. Journal of Personality and Social Psychology, 43, 1230-1242.

Ryff, C. D., \& Singer, B. (1998). The contours of positive human health. Psychological Inquiry, 9, 1-28.

Salovey, P., Rothman, A. J., Detweiler, J. B., \& Steward, W. T. (2000). Emotional states and physical health. American Psychologist, 55, 110121

Sarason, B. R., Sarason, I. G., \& Gurung, R. A. R. (1997). Close personal relationships and health outcomes: A key to the role of social support. In S. Duck (Ed.), Handbook of personal relationships: Theory, research, and interventions (2nd ed., pp. 547-573). New York: Wiley.

Shaefer, M. T., \& Olson, D. H. (1981). Assessing intimacy: The PAIR inventory. Journal of Marital and Family Therapy, 7, 47-60.

Shrauger, J. S., \& Schoeneman, T. J. (1979). Symbolic interactionist view of self-concept: Through the looking glass darkly. Psychological Bulletin, 86, 549-573.

Tangney, J. P., \& Fischer, K. W. (1995). Self-conscious emotions and the affect revolution: Framework and overview. In J. P. Tangney \& K. W. Fischer (Eds.), Self-conscious emotions: The psychology of shame, guilt, embarrassment, and pride (pp. 1-24). New York: Guilford Press.

Taylor, S. E. (1991). Asymmetrical effects of positive and negative events: The mobilization-minimization hypothesis. Psychological Bulletin, 110, $67-85$.
Tesser, A. (2000). On the confluence of self-esteem maintenance mechanisms. Personality and Social Psychology Review, 4, 290-299.

Tesser, A., Millar, M., \& Moore, J. (1988). Some affective consequences of social comparison and reflection processes: The pain and pleasure of being close. Journal of Personality and Social Psychology, 54, 49-61.

Uchino, B. N., Cacioppo, J. T., \& Kiecolt-Glaser, J. K. (1996). The relationship between social support and physiological processes: A review with emphasis on underlying mechanisms and implications for health. Psychological Bulletin, 119, 488-531.

Watson, D., Clark, L. A., \& Tellegen, A. (1988). Development and validation of brief measures of positive and negative affect: The PANAS scales. Journal of Personality and Social Psychology, 54, 1063-1070.

Wieselquist, J., Rusbult, C. E., Foster, C. A., \& Agnew, C. R. (1999) Commitment, pro-relationship behavior, and trust in close relationships. Journal of Personality and Social Psychology, 77, 942-966.

Zautra, A. J., Schultz, A. S., \& Reich, J. W. (2000). The role of everyday events in depressive symptoms for older adults. In G. M. Williamson \& D. R. Shaffer (Eds.), Physical illness and depression in older adults: A handbook of theory, research, and practice (pp. 65-91). New York: Kluwer Academic/Plenum Publishers.

Received January 11, 2003

Revision received January 6, 2004

Accepted February 7, 2004

\section{Correction to Tauer and Harackiewicz (2004)}

The article "The Effects of Cooperation and Competition on Intrinsic Motivation and Performance," by John M. Tauer and Judith M. Harackiewicz (Journal of Personality and Social Psychology, 2004, Vol. 86, No. 6, pp. 849-861), contained two errors.

On page 853, in Table 1, Study 4, in the Task enjoyment row, the mean for the pure coop-4 condition, which is missing, should be 3.65 , and the mean for the individual condition, shown as 3.65 , should be 3.63 . 